\title{
Desenvolvimento do Raciocínio Lógico e Algoritmo Através do Programa Institucional de Bolsas de Iniciação à Docência no Ensino Fundamental
}

\author{
Árllon C. Lima, Decíola F. de Sousa \\ Instituto Ciberespacial - Universidade Federal Rural da Amazônia (UFRA) \\ Av. Presidente Tancredo Neves, 2501. 66077-901. Belém-PA-Brasil. \\ arllonlima@yahoo.com.br, deciola.sousa@ufra.edu.br
}

\begin{abstract}
This article reports the experience of a colleger from the Scholarship Institutional Program of Initiation to Teaching through a course, in which if worked the introduction to logical thinking and algorithm with students of the 5th year of elementary school at a public school. We sought to reach understanding of the content taught, as well as the construction of student knowledge the computational thinking through the use of school computer classroom computers with the help of pseudo-language "Portugol $I D E^{\prime \prime}$ and of playful way using resources didactic and pedagogical as objects of learning.
\end{abstract}

Resumo O presente artigo relata a experiência de um bolsista do Programa Institucional de Bolsas de Iniciação à Docência por meio de um curso, no qual se trabalhou a introdução ao raciocínio lógico e algoritmo com alunos do $5^{\circ}$ ano do ensino fundamental de uma escola pública. Buscou-se alcançar a compreensão do conteúdo ministrado, assim como a construção do conhecimento dos alunos no âmbito do pensamento computacional por meio da utilização dos computadores da sala de informática da escola com auxílio da pseudo-linguagem "Portugol IDE" e de forma lúdica utilizando recursos didático-pedagógicos como objetos de aprendizagem.

\section{Introdução}

A construção do conhecimento pode ser concebida das mais diversas maneiras e áreas de estudo em que ferramentas didáticas são criadas e adaptadas para trabalhar os conteúdos ministrados em sala de aula. Com o auxílio de ferramentas tecnológicas no contexto educacional como, por exemplo, a inserção da sala de informática nas escolas, o processo de ensino e de aprendizagem se tornou mais dinâmico e criativo principalmente através da utilização de softwares que englobam várias áreas do conhecimento e que permitem o desenvolvimento dos alunos, contribuindo para melhorar o rendimento escolar.

Não parece haver dúvidas que a temática sobre o uso das tecnologias na educação é de suma importância nos dias atuais, portanto a utilização do computador na escola, como recurso tecnológico, torna-se uma ferramenta pedagógica no processo de ensino e de aprendizagem [Fugimoto 2009].

Ao falar sobre a utilização da informática e/ou da computação direcionada a educação básica, muitos se prendem as ferramentas básicas que a máquina proporciona, esquecendo-se de princípios computacionais que servem de base para outras matérias 


\section{CBIE-LACLO 2015}

Anais dos Workshops do IV Congresso Brasileiro de Informática na Educação (CBIE 2015)

escolares. O que se encontra na realidade, principalmente em escolas públicas, são profissionais de outras áreas atuando nas salas de informática, com pouco preparo ou conhecimento insuficiente sobre área que os levem a realizar atividades que promovam o desenvolvimento e crescimento educacional dos alunos.

Partindo desse pressuposto, buscou-se através do curso ministrado para alunos do $5^{\circ}$ ano do ensino fundamental trabalhar o raciocínio lógico e a construção do algoritmo, mostrando aos alunos, na prática, novas formas de se adquirir conhecimentos com a utilização de ferramentas tecnológicas, sendo o computador e os softwares utilizados a mediação do processo de ensino e de aprendizagem dos mesmos.

Atualmente, as atenções e questionamentos se voltam para o computador, porque é o mais novo instrumento de mediação a fazer parte do cenário educacional. Os elementos que mais contribuíram para que o computador se tornasse um dos mais versáteis mediadores tecnológicos no campo da Educação foram os programas e os protocolos de comunicação, que recebem o nome de software [Jucá 2006].

A experiência proporcionada pelo Programa Institucional de Bolsas de Iniciação à Docência (PIBID) aos bolsistas da Universidade Federal Rural da Amazônia (UFRA) do curso de Licenciatura em Computação contribui para o crescimento pessoal e profissional dos discentes, por possibilitar o contato direto com o futuro ambiente de trabalho, a sala de informática, e aplicar os conhecimentos adquiridos na universidade. Além de beneficiar os alunos da escola pública com o ensino da lógica e algoritmo e a utilização dos computadores da sala de informática, colocando em prática o que foi trabalhado com o uso da Pseudo-linguagem "Portugol IDE", relacionando os conteúdos ministrados com algumas matérias escolares, contribuindo para o crescimento educacional dentro e fora do ambiente escolar.

O objetivo do artigo é apresentar a experiência dos bolsistas do PIBID através do curso onde foi trabalhado o pensamento computacional, a introdução ao raciocínio lógico, os conceitos de algoritmo, estrutura sequencial e estrutura de seleção, ministrado para alunos da educação básica do $5^{\circ}$ ano do ensino fundamental de uma escola pública. A sala de informática da escola foi utilizada para o desenvolvimento do curso, para execução de atividades com objetos de aprendizagem e construção dos algoritmos.

O artigo apresenta na seção 2 trabalhos relacionados com o tema, a seção 3 detalha a metodologia aplicada no curso, a seção 4 apresenta a avaliação e a análise dos resultados, as considerações finais estão na seção 5 .

\section{Trabalhos Relacionados}

Uma experiência em relação ao trabalho desenvolvido junto ao subprojeto do PIBID da Universidade Estadual do Paraná (UNESPAR) para o ensino da matemática utilizando softwares computacionais é relatada em [Basniak 2014], enfatizando que o aluno além dos conteúdos da disciplina, aprendeu com o uso de ferramentas computacionais de forma mais dinâmica e interativa. Nesse sentido, as tarefas propostas com o uso do computador propuseram mudanças no processo de aprendizagem em que o aluno deixa de meramente repetir algoritmos apresentados pelo professor para buscar respostas às questões apresentadas.

Uma proposta metodológica para a atividade com Números Binários em que tem como objetivo desenvolver habilidades necessárias para prática do Pensamento 


\section{CBIE-LACLO 2015}

Anais dos Workshops do IV Congresso Brasileiro de Informática na Educação (CBIE 2015)

Computacional em crianças do quarto ano do Ensino Fundamental é apresentada por [Campos et al. 2014]. Os autores afirmam que as escolas do ensino fundamental são veículos relevantes para implantação do uso do PC (pensamento computacional), no sentido de incentivar habilidades para desenvolvimento pleno e efetivo do raciocínio lógico-dedutível, principalmente nos primeiros anos escolares.

Existem outros trabalhos que estimulam o pensamento computacional na educação básica, como a "Computação Desplugada". Sem a utilização do computador, [Bezerra 2014] em sua experiência em uma escola pública da Região Metropolitana de Belém através do PIBID da Universidade Federal Rural da Amazônia (UFRA) do curso de Licenciatura em Computação, propôs o ensino da Computação Desplugada no ensino fundamental, explorando também o universo dos algoritmos, enfatizando ser a parte fundamental da computação, por serem os algoritmos que "dizem" como os computadores devem trabalhar. $\mathrm{O}$ autor relata em sua experiência que o contato com a computação desde o ensino fundamental é de grande importância por permitir o desenvolvimento do pensamento computacional, contribuindo para a possibilidade de futuros profissionais na área de computação.

A importância do ensino de Computação na Educação Básica é evidenciada em [França et al. 2012], decorrente das atividades desenvolvidas nos Estágios Curriculares Obrigatórios no curso de Licenciatura em Computação da Universidade de Pernambuco (UPE), no ano de 2011. A metodologia, bem como os resultados obtidos, foram baseados na realização de atividades lúdicas para facilitar o processo de ensinoaprendizagem, através da Computação Unplugged com a finalidade de promover a disseminação do pensamento computacional na educação básica, desenvolvendo as atividades com a implementação de algoritmos. Utilizaram a ferramenta Scratch composta por uma linguagem gráfica de programação, que possibilita a criação de histórias interativas, animações, jogos e o compartilhamento dessas criações na Web, envolvendo os alunos do $9^{\circ}$ ano do Ensino Fundamental da Escola de Aplicação Professora Ivonita Alves Guerra da Universidade de Pernambuco, localizada no agreste meridional do estado de Pernambuco, na cidade de Garanhuns.

De modo geral, os trabalhos evidenciam a inclusão do ensino computacional na educação básica, compartilham aspectos comuns e o objetivo de tornar a aprendizagem mais atrativa com a introdução de algoritmos no ensino fundamental.

\section{Metodologia}

O curso foi realizado para alunos do $5^{\circ}$ ano da escola pública estadual Mário Barbosa, localizada na periferia de Belém-PA, onde os alunos são, na maioria, de origem ribeirinha e de baixa renda, utilizam barco para chegar à cidade e depois ônibus para chegar à Escola ou uma caminhada de $2 \mathrm{~km}$. O curso foi de 40 horas, com (4) quatro aulas diárias durante duas semanas consecutivas.

Das 10 vagas disponíveis para o curso, houve o preenchimento de $100 \%$ de alunos inscritos, oito alunos participaram ativamente durante todas as atividades no curso, ou seja, $80 \%$ dos inscritos obtiveram presença igual ou acima de $75 \%$.

Para que houvesse uma melhor forma de se trabalhar os conteúdos a serem ministrados, no segundo dia de aula, realizou-se uma avaliação diagnóstica para medir o grau de conhecimento dos alunos com relação à matemática, português e raciocínio lógico, possibilitando aos bolsistas recorrer a formas adequadas e adaptar os conteúdos 


\section{CBIE-LACLO 2015}

Anais dos Workshops do IV Congresso Brasileiro de Informática na Educação (CBIE 2015)

das aulas, tomando os devidos cuidados para não prejudicar a compreensão e consequentemente o processo de ensino e de aprendizagem. Na penúltima aula realizouse outra avaliação, com os mesmos conteúdos, para análise da contribuição ou não do curso para os alunos da Escola.

Ensinar algoritmo para alunos do $5^{\circ}$ ano do ensino fundamental foi um grande desafio para os bolsistas, pois mesmo para graduandos em Licenciatura em Computação é um conteúdo considerado complexo por muitos, principalmente pela dificuldade em utilizar a lógica, matemática e interpretação textual importantes para construção de um algoritmo. Pelo grau de complexidade dos conteúdos que foram trabalhados, buscou-se caminhos para facilitar o processo de ensino e de aprendizagem, por meio de jogos e atividades relacionadas a situações do cotidiano.

No curso se trabalhou conceitos básicos de algoritmo como constantes, variáveis, expressões aritméticas, adição, subtração, multiplicação e divisão, ensinando a questão de prioridade; expressões lógicas, operadores e operando; estrutura sequencial e estrutura condicional ou seleção. Além dos comandos básicos de algoritmo como "início", os tipos de variáveis (real, inteiro, texto e caractere), "ler", "escrever" e "fim".

Os exercícios de estrutura sequencial e de seleção foram planejados de acordo com os dados obtidos na avaliação diagnostica das matérias de português, matemática e raciocínio lógico, realizadas no início do curso e com a realidade dos alunos, ou seja, de acordo com a capacidade dos mesmos, por exemplo, na estrutura sequencial os alunos realizaram um algoritmo para a soma entre dois números, e na estrutura de seleção um algoritmo para que mostrasse a média de duas notas e dizer se estava aprovado ou não.

Com o intuito de despertar o interesse, a curiosidade dos alunos e estimular à capacidade de raciocinar, em média, foram realizados de cinco a seis exercícios por dia durante o curso. Em todos os exercícios foi proposto que resolvessem os problemas de forma não obrigatória, deixando com que os alunos da Escola tivessem suas próprias tomadas de ação para que houvesse um melhor desenvolvimento do raciocínio lógico, escolhendo a própria forma de solucionar os problemas, contribuindo assim para o processo de ensino e de aprendizagem.

A plataforma utilizada para a contrução do algortimo foi o IDE (Integrated Development Environment) Portugol, onde os bolsistas instalaram nos computadores da sala de informática da Escola. Através dessa plataforma os alunos da escola puderam colocar em prática os exercícios desenvolvidos durante o curso e verificar os resultados dos mesmos.

Os exercícios e atividades para o desenvolvimento do raciocínio lógico dos alunos foram realizados com situações do dia a dia, facilitando o processo de ensino e de aprendizagem, além de ter sido importante por promover a organização e ordenação do pensamento, contribuindo de maneira significativa para a construção do algoritmo, visto que, um algoritmo é uma sequência lógica de passos ordenados para solução de problemas. Utilizou-se os computadores, que além da prática do que foi ensinado, trabalhou-se com objetos de aprendizagem online, desenvolvendo atividade lúdica para complementar os conteúdos trabalhados no curso. 
CBIE-LACLO 2015

Anais dos Workshops do IV Congresso Brasileiro de Informática na Educação (CBIE 2015)

\section{Avaliação e Análise dos Resultados}

O processo de avaliação diagnostica é importante, pois é um método, por exemplo, de se ter a possibilidade de analisar o nível de aproveitamento de uma unidade ou de determinada parte do conteúdo e dessa forma adaptar a aula em relação aos resultados, tomando decisões de acordo com os problemas identificados, buscando soluções adequadas para uma melhor maneira do professor realizar as aulas e para melhor compreensão dos alunos.

A partir da avaliação diagnostica, realizada com os alunos participantes no início do curso, foi possível criar atividades que estimulassem e desenvolvessem o pensamento lógico com situações do dia a dia, assim como conteúdo de matemática e de interpretação textual (Português), matérias necessárias para realizar a construção do algoritmo.

A Figura 1 apresenta o resultado da primeira avaliação realizada pelos alunos com conteúdo de português, matemática e lógica.

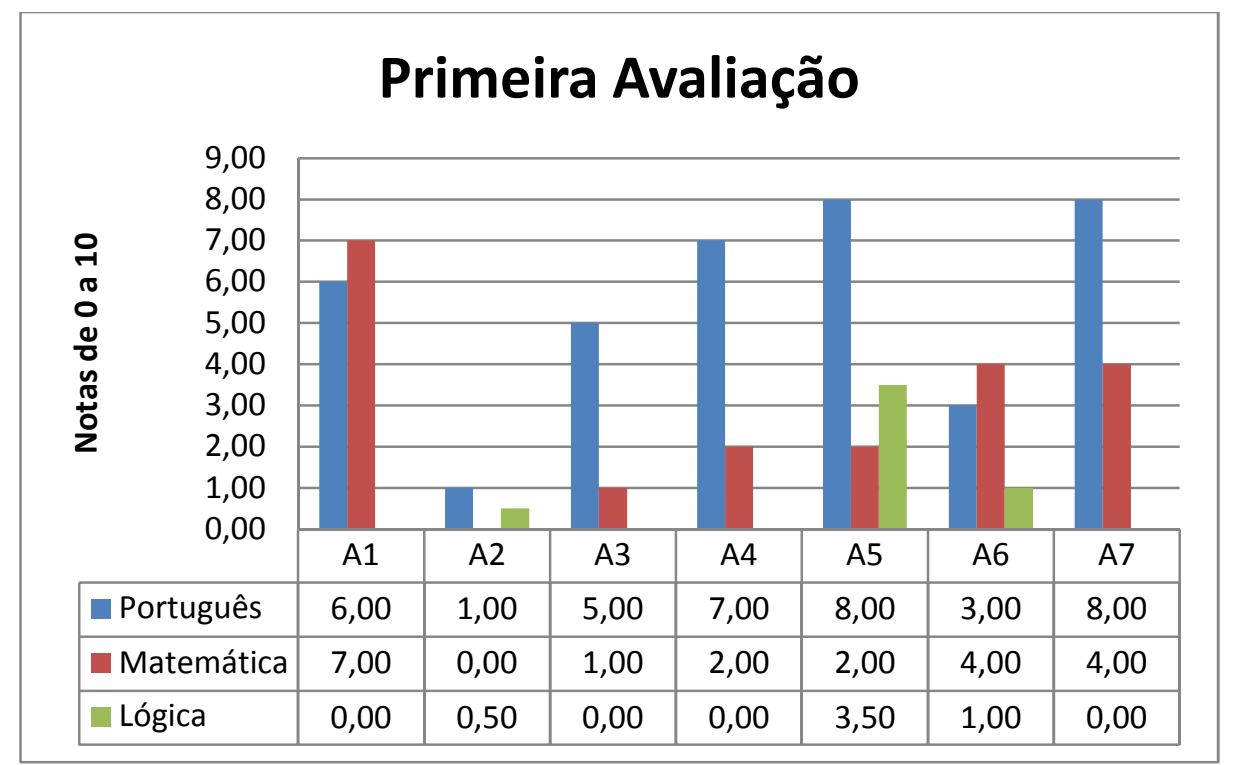

Figura 1: Resultado da primeira avaliação.

As notas apresentadas na Figura 1 demonstram os resultados obtidos pelos alunos na primeira avaliação, onde a média da turma foi 5 . Dos sete alunos que realizaram a primeira avaliação, conforme Figura 1, cinco adquiriram nota maior ou igual a média 5 e dois com notas menores em Português, em Matemática somente um aluno conseguiu nota maior que a média 5 e seis com nota menor e nas questões de Lógica nenhum aluno conseguiu ficar a cima da média 5. É válido ressaltar que as questões produzidas pelos bolsistas nessa primeira avaliação foram de acordo com o grau de escolaridade dos alunos, isto é, para alunos do $5^{\circ}$ ano do ensino fundamental.

Ficou claro que a maioria dos alunos não tinham grandes problemas na matéria de português, porém apresentaram dificuldades em duas matérias essenciais para construção do algoritmo, matemática e lógica. Foi a partir dos resultados obtidos na primeira avaliação que os bolsistas, durante o curso, procuraram se adequar e buscar estratégias para que esse quadro pudesse ser revertido. 
CBIE-LACLO 2015

Anais dos Workshops do IV Congresso Brasileiro de Informática na Educação (CBIE 2015)

No final do curso foi realizada outra avaliação, com o mesmo conteúdo da primeira, um aluno que não realizou a primeira estava presente na segunda, o resultado é apresentado na Figura 2.

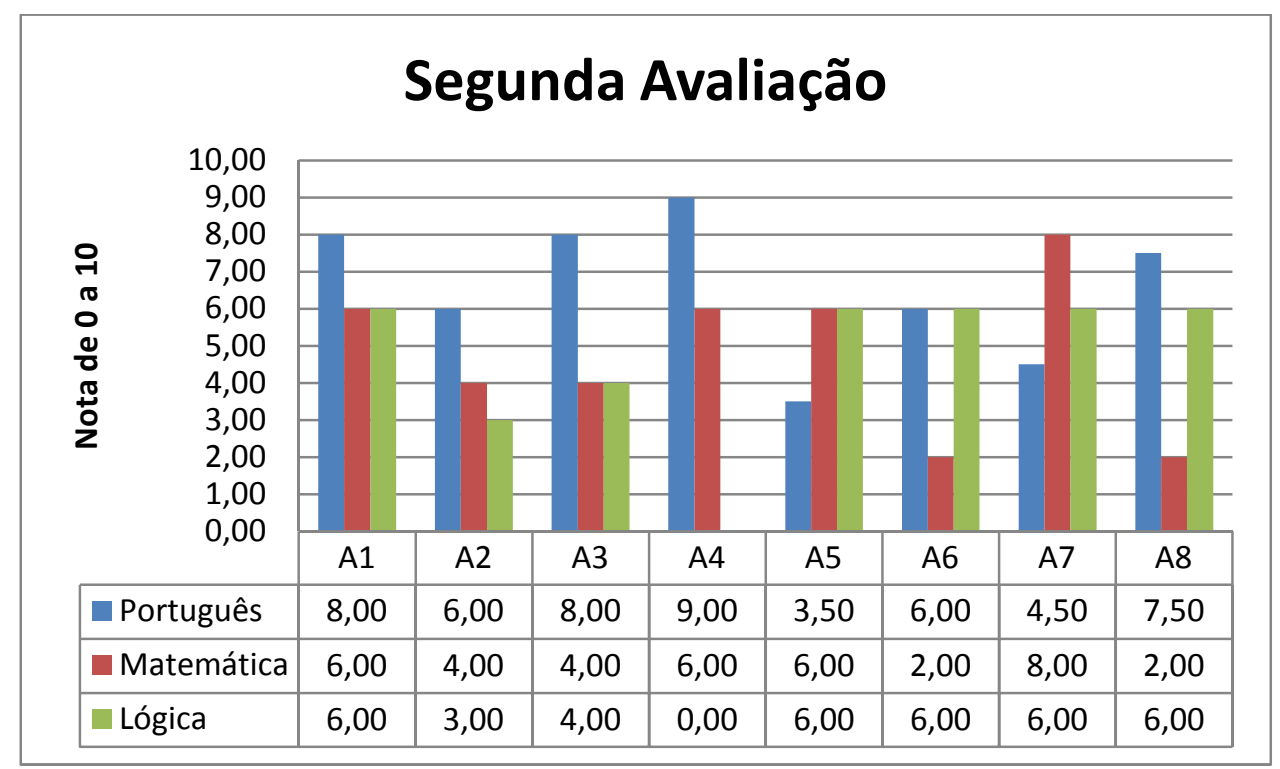

Figura 2: Resultado da segunda avaliação.

As notas apresentadas na Figura 2 demonstram os resultados obtidos pelos alunos na segunda avaliação, onde a média da turma foi 5. Dos oito alunos que realizaram a segunda avaliação, conforme Figura 2, seis obtiveram notas maiores que a média 5 e dois com notas menores em português, quatro com notas maiores que a média 5 e quatro com notas menores em matemática e cinco com notas maiores que a média 5 e três com notas menores em lógica.

A Figura 3 compara a média da turma nas duas avaliações realizadas pelos bolsistas com os alunos na Escola.

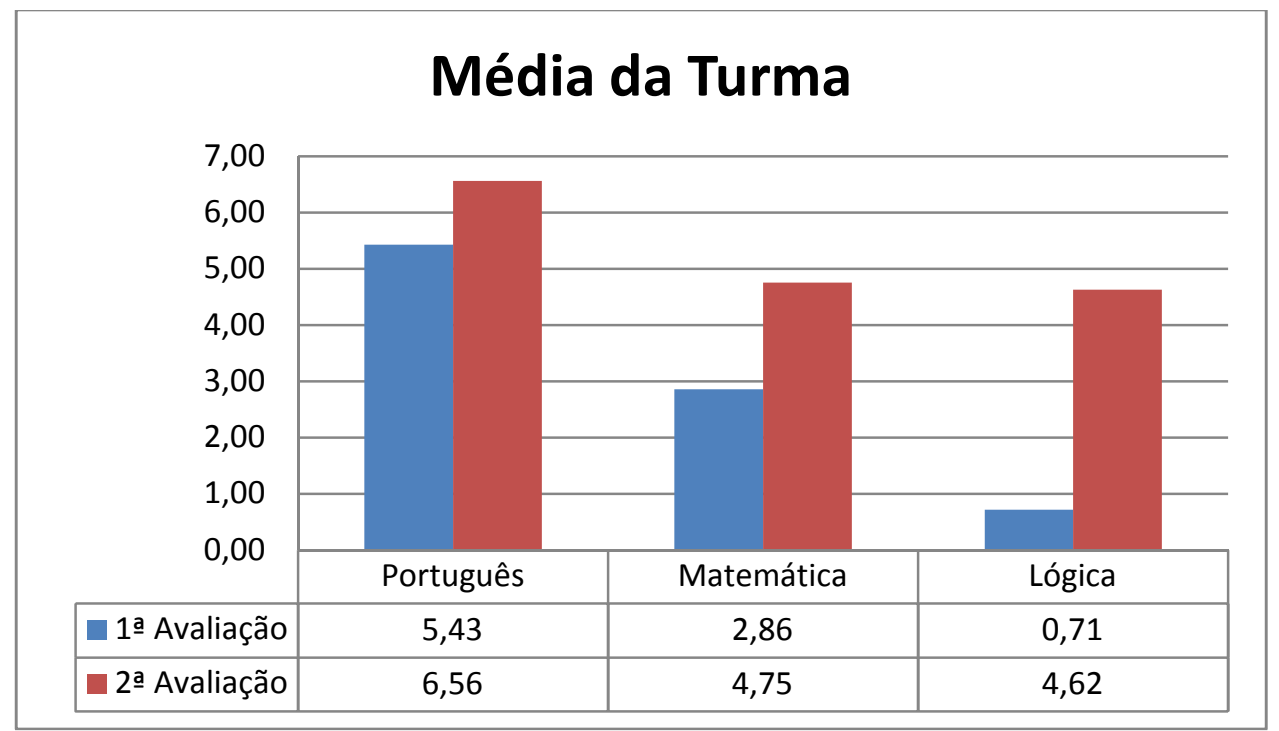

Figura 3: Comparação da média da turma.

Em todas as matérias houve uma melhora na média da turma na segunda avaliação, como mostra a Figura 3, principalmente em matemática e lógica. 
Para confirmar a significância destes resultados, os autores aplicaram a ferramenta de análise Teste T para as notas das avaliações, somente para o universo de alunos que realizaram a primeira e a segunda avaliação, através da planilha eletrônica Excel, para amostras pareadas considerando uma significância de 5\%. A Tabela 1 ilustra os resultados da análise da avaliação de lógica.

Tabela 1. Teste T para avaliação de lógica

\begin{tabular}{|l|r|r|}
\hline \multicolumn{3}{|c|}{} \\
\multicolumn{3}{|c|}{ Teste-t: duas amostras em par para médias } \\
\hline \multicolumn{3}{|c|}{} \\
\hline & $1^{a}$ & \multicolumn{1}{|c|}{$2^{a}$} \\
\hline Média & avaliação & avaliação \\
\hline Variância & 0,7142857 & 4,4285714 \\
\hline Observações & 1,6547619 & 5,2857143 \\
\hline Correlação de Pearson & 7 & \\
\hline Hipótese da diferença de média & 0,3582541 & \\
\hline gl(grau de liberdade) & 0 & \\
\hline Media da diferença & 6 & \\
\hline $\mathrm{P}(\mathrm{T}<=t)$ uni-caudal & $-4,4754474$ & \\
\hline$t$ crítico uni-caudal & 0,0021064 & \\
\hline $\mathrm{P}(\mathrm{T}<=t)$ bi-caudal & 1,9431803 & \\
\hline $\mathrm{t}$ crítico bi-caudal & 0,0042128 & \\
\hline
\end{tabular}

A aplicação do Teste $\mathrm{T}$ da Tabela 1 permitiu verificar que é possível considerar que existe diferença estatisticamente significativa entre as médias da avaliação de lógica do grupo de experimento no início e depois de terem participado do curso. Há diferença na média da Tabela 1 em relação a média da turma porque os valores considerados foram dos alunos que realizaram as duas avaliações. No caso, a média deste grupo na avaliação de lógica após o curso se apresentou melhor que sua média no início.

Apesar das dificuldades encontradas pelos bolsistas em adaptar as aulas, conseguiu-se através do ensino da lógica e algoritmo, assim como na construção do pensamento computacional, que os alunos pudessem no final do curso adquirir notas melhores, resultando um bom desempenho na $2^{\mathrm{a}}$ Avaliação, principalmente nas matérias de lógica e matemática.

A avaliação da construção do algoritmo foi realizada individualmente no último dia de aula e de acordo com que foi trabalhado durante o curso através da PseudoLinguagem Portugol IDE, pontuando todo e qualquer comando correto feito nos pequenos algoritmos construídos pelos alunos, mesmo que não tivessem completos. Assim como em outras experiências realizadas, alguns alunos se destacaram e conseguiram notas significativas.

Dos oito alunos que realizaram a avaliação de algoritmo, 50\% conquistaram notas acima da média 5. A Figura 4 expõe as notas individuais dos alunos. 
CBIE-LACLO 2015

Anais dos Workshops do IV Congresso Brasileiro de Informática na Educação (CBIE 2015)

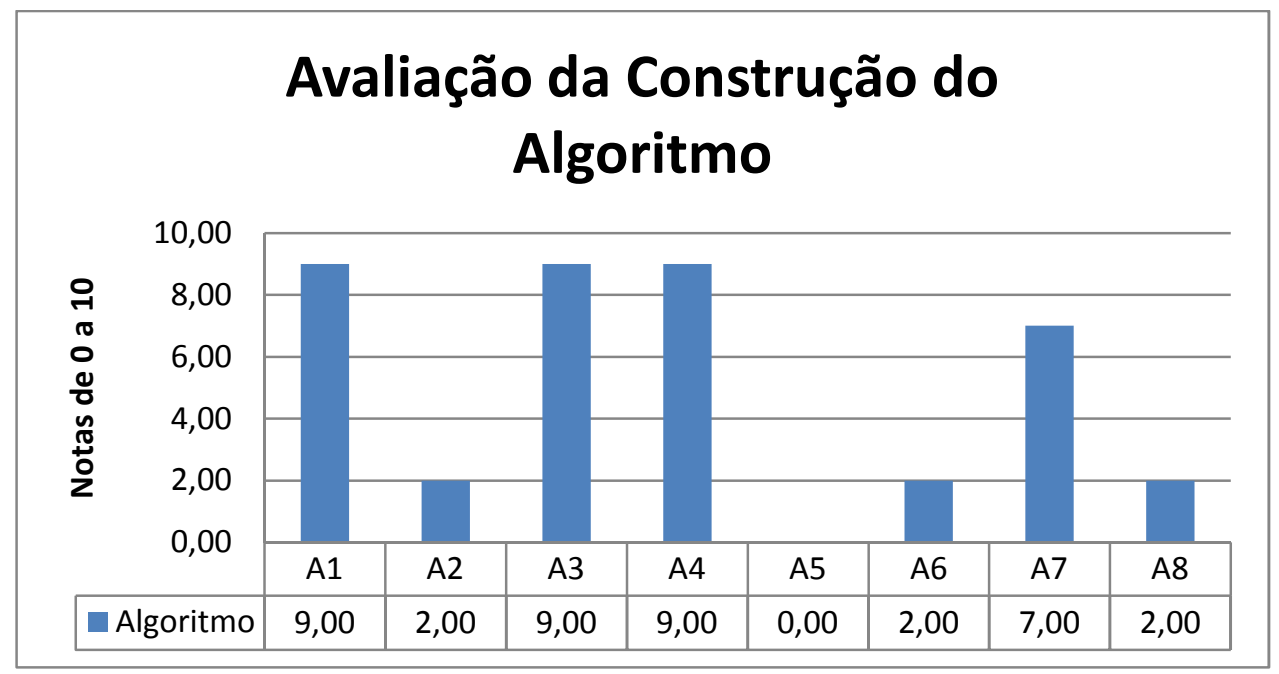

Figura 4: notas individuais dos alunos na construção do algoritmo.

As notas apresentadas na Figura 4 demonstram que os alunos obtiveram notas relevantes na construção dos algoritmos, onde a média da turma foi 5. Na avaliação do algoritmo quatro dos oito alunos ficaram acima da média 5, onde três conseguiram realizar o algoritmo quase completo, obtendo a nota 9. Os outros quatro alunos ficaram com notas inferiores a média 5 e um aluno não conseguiu realizar o algoritmo no tempo estipulado de uma aula, porém todos conseguiram desenvolver o algoritmo depois do término da avaliação.

No final do curso foi realizado um questionário com onze perguntas em que os alunos marcaram "sim" ou "não". Das onze perguntas destaca-se quatro, representadas na Figura 5.

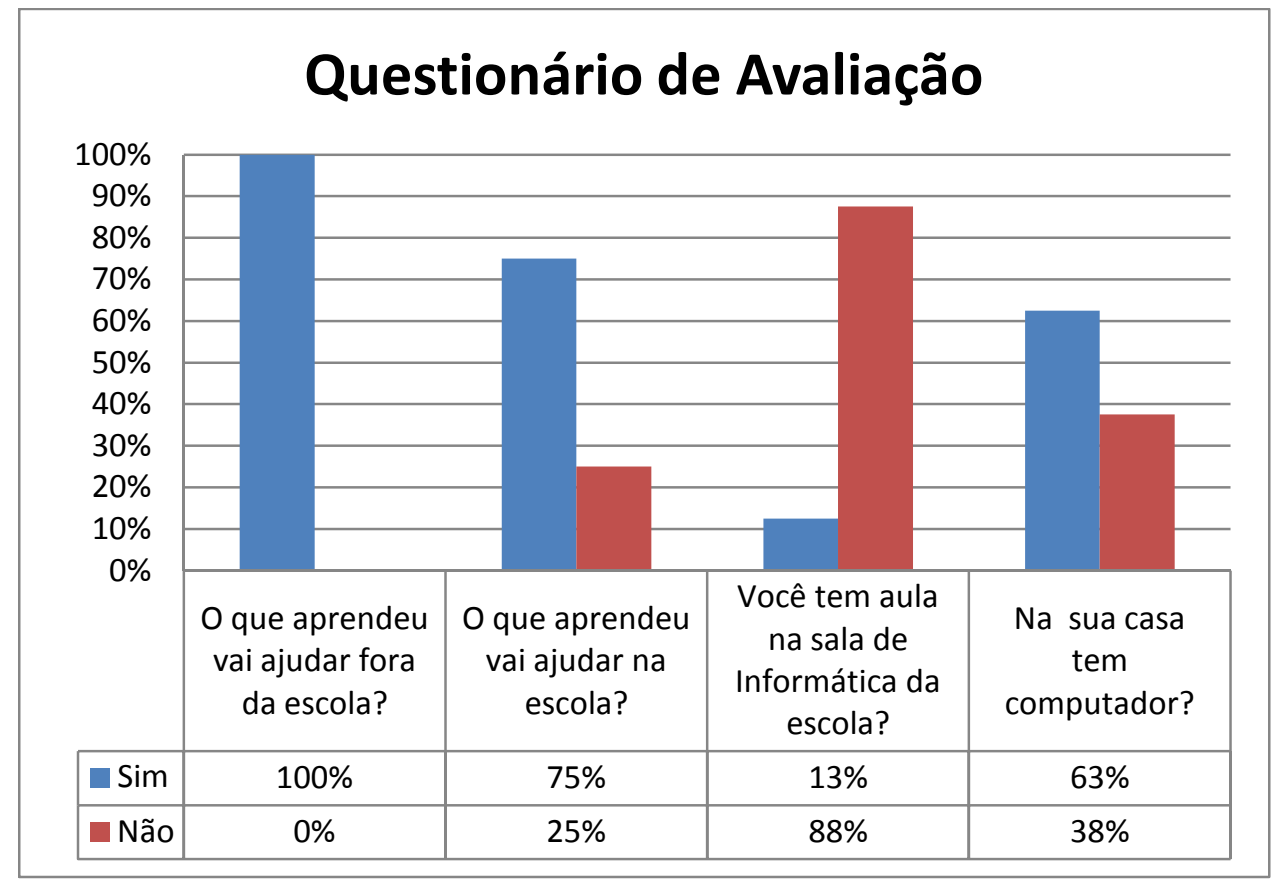

Figura 5: Questionário de avaliação do curso.

Com os resultados obtidos, conforme Figura 5, percebe-se a importância do curso para os alunos da escola. Durante o curso os bolsistas desenvolveram atividades 


\section{CBIE-LACLO 2015}

Anais dos Workshops do IV Congresso Brasileiro de Informática na Educação (CBIE 2015)

que estavam relacionadas ao cotidiano e as próprias matérias escolares dos alunos como o português e matemática. Todos os alunos, ou seja, $100 \%$ concordaram que os conhecimentos adquiridos vão ajudar fora da escola e $75 \%$ acreditam que irão ajudar também na escola. Para que se pudesse fazer a intervenção na escola, foi necessário que os próprios bolsistas concertassem, limpassem e formatassem os computadores, pois estavam cheios de poeira, poucos em funcionamento e parados por muito tempo, ou seja, os alunos da escola certamente não usufruíam da sala de informática para atividades escolares, o que foi constatado através do questionário no qual dos oito alunos, sete, que corresponde a $88 \%$, afirmaram que não tinham aulas na sala de informática.

Apesar de $63 \%$ dos alunos responderem terem computadores em casa, durante o curso percebeu-se que muitos estavam tendo o primeiro contato com o computador, onde apresentaram grandes dificuldades principalmente em digitar as palavras de maneira correta, mesmo que copiando do quadro, ou seja, alguns eram totalmente analfabetos digitais, não sabendo realizar coisas simples como copiar e colar.

Os resultados foram satisfatórios, motivando todos envolvidos a continuar com o projeto e contribuindo para o processo de ensino e de aprendizagem, principalmente para os futuros licenciados em computação.

\section{Considerações finais}

O artigo apresentou o ensino de lógica e algoritmo na escola pública através de um curso para alunos do $5^{\circ}$ ano onde se mostrou diferentes formas de se utilizar o computador e de como é benéfico para o processo de ensino e de aprendizagem, sendo um instrumento importante para construção do conhecimento, que auxilia e dá suporte aos bolsistas do Programa Institucional de Bolsas de Iniciação a Docência (PIBID) durante as atividades desenvolvidas na sala de informática de uma escola, contribuindo para melhorar a aprendizagem dos alunos nas escolas públicas nas matérias básicas como português e matemática.

O uso de computadores durante curso possibilitou que os alunos pudessem ter novas formas de aprender e solucionar pequenos problemas relacionados ao cotidiano e as suas próprias matérias escolares. Os estímulos desenvolvidos contribuíram para que pudessem concretizar a construção de algoritmos, além de fortalecer conhecimentos sobre a ferramenta (computador). A utilização dessa ferramenta na educação torna-se positiva se utilizada de maneira correta, buscando proporcionar o processo de ensino e de aprendizagem mais produtivo, dinâmico, criativo e atrativo tanto para os bolsistas quanto para os alunos da escola.

Para licenciados em computação ainda são grandes os desafios a enfrentar. Muitas escolas principalmente as públicas, os responsáveis pelos laboratórios de informática não realizam atividades que possam contribuir para o crescimento do rendimento escolar dos alunos e muito menos para disseminação do pensamento computacional, pois basicamente não são conhecedores da área, deixando de utilizar um espaço que pode ser de tanto valor para o processo de ensino e de aprendizagem. A sala de informática da escola que se realizou o curso, por exemplo, a maioria dos computadores estava parados por falta de manutenção e por estarem muito tempo sem serem utilizados, sendo necessário que os próprios bolsistas do PIBID formassem um mutirão para concertá-los para que fosse possível realizar as atividades na escola. 
O PIBID proporciona aos bolsistas a oportunidade de estabelecer contato com o ambiente escolar e futuro local de trabalho, contribuindo de maneira significativa para o crescimento pessoal e acadêmico de futuros profissionais na área de educação em computação na educação básica, aprendendo a ter maiores responsabilidades descobrindo o verdadeiro valor de ensinar e de como proceder no processo de ensino e de aprendizagem, tendo maior sensibilidade de como se adaptar a situações presentes no cotidiano escolar e dos próprios alunos, buscando sempre abordar os conhecimentos obtidos de acordo com o contexto e a realidade presente.

Como trabalho futuros pretende-se realizar o curso para alunos do ensino médio e analisar os resultados.

\section{AGRADECIMENTOS}

O presente trabalho foi realizado com o apoio do Programa Institucional de Bolsa de Iniciação à Docência - PIBID, da CAPES - Coordenação de Aperfeiçoamento de Pessoal de Nível Superior - Brasil.

\section{REFERÊNCIAS BIBLIOGRÁFICAS}

Basniak, M. I. (2014). Tecnologias na Formação de Professores de Matemática: Uma Experiência na Iniciação a Docência. In $3^{\circ}$ Congresso Brasileiro de Informática na Educação (CBIE), 20 $0^{\mathrm{a}}$ Workshop de Informática na Escola (WIE). Dourado-MS, Brasil.

Bezerra, F. (2014). Bem Mais que os Bits da Computação Desplugada. In $3^{\circ}$ Congresso Brasileiro de Informática na Educação (CBIE), $20^{\text {a }}$ Workshop de Informática na Escola (WIE). Dourado-MS, Brasil.

Campos, G. M.; Cavalheiro, S.; Foss, L.; Pernas, A. M.; Piana, C. F. B.; Aguiar, M.; Bois, A. D.; Reise, R. (2014). Organização de Informações via Pensamento Computacional: Relato de Atividade Aplicada no Ensino Fundamental. In $3^{\circ}$ Congresso Brasileiro de Informática na Educação (CBIE), 20 a Workshop de Informática na Escola (WIE). Dourado-MS, Brasil.

Fugimoto, Sonia M. A. (2009). O computador na escola: professor de educação básica e sua prática pedagógica. In Seminário de Pesquisa PPE. Maringá-PR, Brasil.

França, R. S.; Silva, W. C.; Amaral, H. J. C. (2012). Ensino de Ciência da Computação na Educação Básica: Experiências, Desafios e Possibilidades. In XX Workshop sobre Educação em Computação, Curitiba. Anais do XXXII CSBC, Brasil.

Jucá. Sandro C. S. (2006). A relevância dos softwares educativos na educação profissional. .In Ciência e Cognição Vol. 08:22-28. ISSN 1806-5821. 